УДК 364.632-053.4:616.89-008.441.44:364-785.14:614.253.4

Для цитирования: Руженкова В.В., Руженков В.А. Влияние домашнего физического насилия, перенесенного в дошкольном возрасте, на социальную адаптацию и суицидальное поведение студентов-медиков. Сибирский вестник психиатрии и наркологии. 2019; 2 (103): 55-64. https://doi.org/10.26617/1810-3111-2019-2(103)-55-64

\title{
Влияние домашнего физического насилия, перенесенного В дошкольном возрасте, на социальную адаптацию и суицидальное поведение студентов-медиков
}

\section{Руженкова В.В., Руженков В.А.}

Белгородский государственный наџиональный исследовательский университет

Россия, 308015, Белгород, ул. Победы, 85

\section{PEЗЮME}

Введение. Насилие, перенесенное в детском возрасте, является неблагоприятным фактором, приводящим к нарушениям социальной адаптации, формированию пограничных психических расстройств и суицидального поведения. Цель исследования: разработка рекомендаций по профилактике суицидального поведения у студентов-медиков на основе изучения дезадаптирующих факторов и их взаимосвязи с перенесенным в дошкольном возрасте физическим насилием в семье. Материал и методы. Медико-социологическим и психометрическим методами обследовано 275 русскоязычных студентов-медиков в возрасте $20-32(22,1 \pm 1,6)$ года: $195(70,9 \%)$ лиц женского и $80(29,1 \%)$ лиц мужского пола, воспитанных в формально благополучных семьях. В выборку включено 85 (30,9\%) человек, перенесших до 7-летнего возраста в семье физическое насилие основная группа (61 женщина и 24 мужчины) и 157 (57,1\%) человек без физического насилия (111 женщин и 46 мужчин) - контрольная группа. Оставшиеся 33 (12\%) человека, указавших на психологическое давление со стороны родителей в дошкольном возрасте, в исследование не включались. Результаты. При неблагоприятных условиях воспитания формируются высокий уровень цинизма и враждебности, а также затруднения в социальной адаптации в большинстве социальных сфер. Более чем в половине случаев $(52,9 \%)$ социальная дезадаптация и конфликтные отношения в семье обусловливали формирование суицидального поведения (внутренних форм - 47,1\% и суицидальных попыток - 8,3\%). Корреляционный анализ выявил прямую зависимость суицидального поведения со степенью неудовлетворенности отношениями с родителями и обратную зависимость - с уровнем самоуважения. Заключение. Полученные данные могут быть положены в основу дифференцированного подхода к профилактике суицидального поведения и социально-психологической дезадаптации лиц юношеского возраста, воспитывающихся в условиях семейной жестокости.

Ключевые слова: студенты-медики, физическое насилие, дошкольный возраст, социальная фрустрированность, самоуважение, суицидальное поведение.

\section{ВВЕДЕНИЕ}

По данным ООН [1], насилие в отношении детей - широко распространенное явление в мире, ему подвергается фактически $10 \%$ школьников, причем этот показатель ежегодно растет. Домашнее насилие, перенесенное в детском возрасте [2], оказывает существенное влияние на поведение и социальную адаптацию в подростковом возрасте (плохие отношения со сверстниками, повышенная агрессивность, тревожность, недовольство собою, делинквентное и аддиктивное поведение, а также применение насилия в межличностных отношениях). В настоящее время под насилием и жестоким обращением над детьми понимаются как наиболее распространенные его формы [3], такие как физическое, психологическое и сексуальное, так и новые - насилие и эксплуатация детей посредством информационных и коммуникационных технологий.
В России семейное насилие по отношению к детям характеризуется как проблема национальной безопасности, влияющая на демографическую ситуацию [4]. Насилие в семье представляет собой многогранное социальное явление [5], предстающее в различных формах (психологическое, экономическое, физическое, бытовое, сексуальное и др.), и является неблагоприятным социальным фактором, обусловливающим развитие в подростковом возрасте психических расстройств [6]. Причем семейное насилие осуществляется также и в благополучных семьях, с достаточным материальным уровнем обеспечения, родителями, имеющими высшее образование и занимающими высокое социальное положение [7, 8].

У подростков, пострадавших в результате жестокого обращения, обнаруживаются устойчивые невротические расстройства (нарушения сна, тревога, фобии, дезадаптивные копинг- 
стратегии), приводящие к социальной дезадаптации [9], и отмечается высокий риск совершения противоправных действий [10] и суицидального поведения [11].

Литературные данные свидетельствуют, что у студентов-медиков выявляется высокий уровень учебного стресса [12]. Более того, [13] стресс, тревога и депрессия широко распространены уже среди поступающих в медицинские институты. Наиболее высокая распространенность стресса характерна в течение первых трех лет обучения с постепенным снижением от $58,3 \%$ до $56,6 \%$ на четвертом курсе и до $25 \%$ на шестом курсе [14]. Наибольший стресс у студентов вызывает ряд факторов: конкуренция с сокурсниками, давление со стороны преподавателей и семьи, увеличение нагрузки перед экзаменами, большие объемы изучаемой информации, недостаток времени для повторения материала, неполучение ожидаемых оценок, слишком долгое обучение, необходимость работы с трупным материалом и жесткий распорядок дня, а также недостаточность навыков планирования времени и самодисциплины, неспособность устанавливать приоритеты [15].

Высокий уровень учебного стресса приводит к эмоциональному выгоранию студентовмедиков [16, 17], негативно сказывается на общем состоянии здоровья и академической успеваемости $[18,19,20]$, является причиной развития тревоги и депрессии, вызывает срыв процессов психической адаптации [21]. В результате у большого числа студентов-медиков, число их варьирует от 40,7\% [22] до 66\% [12], отмечаются суицидальные мысли в результате снижения социальной активности [23, 24].

\section{ЦЕЛЬ ИССЛЕДОВАНИЯ}

Целью исследования являлась разработка рекомендаций по профилактике суицидального поведения у студентов-медиков на основе изучения дезадаптирующих факторов и их взаимосвязи с перенесенным в дошкольном возрасте физическим насилием в семье.

\section{МАТЕРИАЛЫ И МЕТОДЫ}

Нами обследована выборка, состоящая из 275 русскоязычных студентов-медиков старших курсов в возрасте 20-32 $(22,1 \pm 1,6)$ года, из них 195 (70,9\%) лиц женского и 80 (29,1\%) лиц мужского пола, воспитанных в формально благополучных семьях (стабильное материальное и достаточное финансовое обеспечение, высшее образование у большинства родителей, все родители имеют профессию и работают), объединенных общими интересами.
Из числа обследованных было выделено 85 $(30,9 \%)$ человек, перенесших до 7-летнего возраста физическое насилие - основная группа (61 женщина и 24 мужчины) и $157(57,1 \%)$ человек без физического насилия в семье в дошкольном возрасте (111 женщин и 46 мужчин) - группа сравнения.

По субъективной оценке степени выраженности физического насилия мы разделили основную группу на 2 подгруппы: 1-я подгруппа - с выраженным насилием (по самооценке 5-10 баллов) - 25 человек; 2-я подгруппа - с легким насилием (2-4 балла) - 60 человек. Оставшиеся $33(12 \%)$ человека указывали на наличие в дошкольном возрасте только психологического давления со стороны родителей, поэтому в исследование не включались.

Основными методами исследования были медико-социологический (анонимное анкетирование при помощи авторской анкеты, включающей социально-демографические сведения, информацию о перенесенном насилии, его формах и субъективной оценке степени выраженности по 10-балльной шкале: от 0 (отсутствие) до 10 (выраженное насилие) баллов, об особенностях социальной адаптации, виктимности и суицидальном поведении), психометрический (шкала враждебности Кука, шкала самоуважения Розенберга, шкала социальной фрустрации Вассермана).

Суицидологическая оценка была проведена с привлечением критериев, предложенных А.Г. Амбрумовой и В.А. Тихоненко (1980).

Статистическая обработка базы данных проводилась методами непараметрической статистики: описательная статистика, критерий $\chi^{2}$ с поправкой Йетса для таблиц сопряженности $2 \times 2$, отношение шансов, коэффициент ранговой корреляции Спирмена, при помощи пакета прикладных статистических программ Statistica 6.0 .

\section{РЕЗУЛЬТАТЫ И ОБСУЖДЕНИЕ}

Сочетание физического насилия, перенесенного в дошкольном возрасте у студентовмедиков основной группы с психологическим и сексуальным видами насилия представлено в таблице 1.

Установлено, что во всех случаях выраженное физическое насилие сочеталось с психологическим: в 76\% случаев с выраженным (5-10 баллов), в 24\% - с легким (1-4 балла). Кроме того, в 1 (4\%) случае имело место выраженное сексуальное насилие (10 баллов) и в $2(8 \%)-$ легкое (2 балла). 


\section{Сочетание физического насилия с другими видами насилия у студентов-медиков}

Т а б ли ц а 1

\begin{tabular}{|l|c|c|c|c|}
\hline \multirow{2}{*}{$\begin{array}{c}\text { Тип насилия } \\
\text { (выраженность в баллах) }\end{array}$} & \multicolumn{2}{|c|}{ Физическое насилие (2-4 балла), $\mathrm{n}=60$} & \multicolumn{2}{|c|}{ Физическое насилие $(5-10$ баллов), $\mathrm{n}=25$} \\
\hline Психологическое $(2-4)$ & $\mathrm{n}$ & $\%$ & $\mathrm{n}$ & $\%$ \\
\hline Психологическое $(5-10)$ & 22 & 36,7 & 6 & 24,0 \\
\hline Сексуальное (2-4) & 15 & 25,0 & 19 & 76,0 \\
\hline Сексуальное (5-10) & 2 & 1,7 & 2 & 8,0 \\
\hline
\end{tabular}

Легкое физическое насилие (2-4 балла) в $25,0 \%$ случаев сочеталось с выраженным психологическим насилием и в $36,7 \%$ - с легким психологическим. Кроме того, в 3 случаях наблюдалось сексуальное насилие.

Анализ содержания перенесенного физического насилия (5-10 баллов) показал, что в 11 (44\%) случаях обследуемые часто $(10-40 \%)$ периодически получали шлепки, удары ремнем, подзатыльники. 10 (40\%) опрошенных сообщили, что их периодически избивали рукой или ремнем. Кроме того, за проступок их ставили в угол, с ними обращались грубо и жестоко, с принуждением, оказывали на них психологическое давление (угрозы, оскорбления, унижения). При легком физическом насилии обследу- емые претерпевали в отношении себя те же действия, только в более мягкой форме.

Изучение враждебности по шкале Кука (табл. 2) показало, что в 1-й подгруппе высокий уровень цинизма наблюдался в $16 \%$ случаев, а в контрольной группе - только у $1,9 \%$ $\left(\chi^{2}=8,08, p=0,005 ;\right.$ OR=9,8, 95\% CI=1,7-60,3). Причем вероятность формирования высокого уровня цинизма при воспитании в неблагоприятных условиях (жестокость в семье отмечалась до достижения ребенком 7-летнего возраста) почти в 10 раз выше, чем при воспитании в нормальной семейной обстановке. Статистически значимых различий между 1-й и 2-й подгруппами не выявлено.

Т а б ли ц а 2 Уровни цинизма, агрессивности и враждебности в основной и контрольной группах студентов-медиков

\begin{tabular}{|c|c|c|c|c|c|c|c|c|c|c|}
\hline \multirow[t]{3}{*}{ Уровень } & \multicolumn{4}{|c|}{\begin{tabular}{|c|} 
Основная \\
группа \\
\end{tabular}} & \multirow{2}{*}{\multicolumn{2}{|c|}{$\begin{array}{c}\begin{array}{c}\text { Контрольная } \\
\text { группа }\end{array} \\
\text { 3-я подгруппа }\end{array}$}} & \multirow{2}{*}{\multicolumn{2}{|c|}{ Различия [1-3] }} & \multirow{2}{*}{\multicolumn{2}{|c|}{ Различия [2-3] }} \\
\hline & \multicolumn{2}{|c|}{ 1-я подгруппа } & \multicolumn{2}{|c|}{ 2-я подгруппа } & & & & & & \\
\hline & $\mathrm{n}$ & $\%$ & $\mathrm{n}$ & $\%$ & $\mathrm{n}$ & $\%$ & $\chi^{2}$ & $\mathrm{p}$ & $\chi^{2}$ & $\mathrm{p}$ \\
\hline \multicolumn{11}{|c|}{ Цинизм } \\
\hline Высокий & 4 & 16,0 & 2 & 3,4 & 3 & 1,9 & 8,080 & 0,005 & $* * *$ & $* * *$ \\
\hline Средний & 19 & 76,0 & 53 & 88,3 & 130 & 82,8 & $* * *$ & $* * *$ & $* * *$ & $* * *$ \\
\hline Тенденция к низкому & 2 & 8,0 & 5 & 8,3 & 24 & 15,3 & $* * *$ & $* * *$ & $* * *$ & $* * *$ \\
\hline \multicolumn{11}{|c|}{ Агрессивность } \\
\hline Высокая & - & - & - & - & 2 & 1,3 & $* * *$ & $* * *$ & $* * *$ & $* * *$ \\
\hline Средняя & 11 & 44,0 & 24 & 40,0 & 69 & 43,9 & $* * *$ & $* * *$ & $* * *$ & $* * *$ \\
\hline Тенденция к низкой & 13 & 52,0 & 36 & 60,0 & 82 & 52,2 & $* * *$ & $* * *$ & $* * *$ & $* * *$ \\
\hline Низкая & 1 & 4,0 & - & - & 4 & 2,5 & $* * *$ & $* * *$ & $* * *$ & $* * *$ \\
\hline \multicolumn{11}{|c|}{ Враждебность } \\
\hline Высокая & 1 & 4,0 & - & -1 & 8 & 5,1 & $* * *$ & $* * *$ & $* * *$ & $* * *$ \\
\hline Средняя & 14 & 56,0 & 40 & 66,7 & 47 & 29,9 & 5,457 & 0,02 & 22,879 & 0,0005 \\
\hline Тенденция к низкой & 8 & 32,0 & 17 & 28,3 & 88 & 56,1 & 4,087 & 0,043 & 12,269 & 0,001 \\
\hline Низкая & 2 & 8,0 & 3 & 5,0 & 14 & 8,9 & $* * *$ & $* * *$ & $* * *$ & $* * *$ \\
\hline
\end{tabular}

П р и м е ч а н и е. *** - Различия статистически незначимые.

В общей сложности в основной группе преобладал средний уровень враждебности - 54 $(63,5 \%)$ человека, в контрольной группе он выявлен у 47 (29,9\%) человек. Обнаруженные различия были статистически значимы $\left(\chi^{2}=24,229, \mathrm{p}=0,0005 ; \mathrm{OR}=4,1,95 \% \mathrm{CI}=2,3-7,4\right)$. Таким образом, установлено, что при воспитании ребенка в дошкольном возрасте в семьях с жестоким обращением почти в 2/3 случаев формируется личность со средним уровнем враждебности. Вероятность формирования среднего уровня враждебности при воспитании с насилием более чем в 4 раза выше, чем в семьях с благоприятными условиями. Аналогичные данные получены нами и в 1-й подгруппе $(\mathrm{OR}=2,98,95 \% \mathrm{CI}=1,2-7,6)$. 
Уровень враждебности во 2-й подгруппе по сравнению с контрольной группой был выше $\left(\chi^{2}=22,879, p=0,0005 ; \mathrm{OR}=4,7,95 \% \mathrm{CI}=2,4-9,3\right)$. Более того, легкое физическое насилие над ребенком в семье в дошкольном возрасте обусловливает вероятность формирования среднего уровня враждебности более чем в 4 раза, чем при воспитании в благоприятной семейной атмосфере. При благоприятных условиях воспитания более чем в половине случаев $(56,1 \%)$ враждебность характеризовалась тенденцией к низкой $\left(\chi^{2}=12,269, \quad \mathrm{p}=0,001 ; \quad \mathrm{OR}=3,2, \quad 95 \%\right.$ $\mathrm{CI}=1,6-6,5)$ с вероятностью, более чем в 3 раза превышающей аналогичный показатель при воспитании даже с легким насилием. Выявленные личностные особенности будут затруднять социально-психологическую адаптацию.

Результаты, полученные по шкале изучения социальной фрустрации Вассермана, представлены в таблице 3 .

Т а бл и ц 3

Сравнительные характеристики социальной фрустрированности в основной и контрольной группах (критерий Манна-Уитни) студентов-медиков

\begin{tabular}{|l|c|c|c|c|c|c|c|}
\hline \multirow{2}{*}{ Сфера социальной фрустрации } & \multicolumn{3}{c|}{ Основная группа } & \multicolumn{3}{|c|}{ Контрольная группа } & \multirow{2}{*}{$\mathrm{p}$} \\
\cline { 2 - 7 } & $\mathrm{Me}$ & $\mathrm{Q} 25$ & $\mathrm{Q} 75$ & $\mathrm{Me}$ & $\mathrm{Q} 25$ & $\mathrm{Q} 75$ & \\
\hline Своим образованием & 2,0 & 2,0 & 3,0 & 2,0 & 1,0 & 2,0 & 0,0091 \\
\hline Отношениями с коллегами & 2,0 & 2,0 & 3,0 & 2,0 & 1,0 & 2,0 & 0,0000 \\
\hline Взаимоотношениями с администрацией & 2,0 & 2,0 & 3,0 & 2,0 & 1,0 & 2,0 & 0,0009 \\
\hline Взаимоотношениями с преподавателями & 2,0 & 2,0 & 3,0 & 2,0 & 1,0 & 2,0 & 0,0003 \\
\hline Содержанием своей работы (учебы) в целом & 2,0 & 2,0 & 3,0 & 2,0 & 2,0 & 2,0 & 0,0003 \\
\hline Условиями профессиональной деятельности & 2,0 & 2,0 & 4,0 & 2,0 & 2,0 & 3,0 & 0,0263 \\
\hline Своим положением в обществе & 2,0 & 2,0 & 3,0 & 2,0 & 1,0 & 2,0 & 0,0001 \\
\hline Материальным положением & 2,0 & 2,0 & 4,0 & 2,0 & 2,0 & 3,0 & 0,0221 \\
\hline Жилищно-бытовыми условиями & 2,0 & 1,0 & 3,0 & 2,0 & 1,0 & 2,0 & $* * *$ \\
\hline Отношениями с родителями & 2,0 & 1,0 & 2,0 & 1,0 & 1,0 & 2,0 & 0,0002 \\
\hline Обстановкой в обществе (государстве) & 3,0 & 2,0 & 4,0 & 2,0 & 2,0 & 3,0 & 0,0025 \\
\hline Отношениями с друзьями, знакомыми & 2,0 & 1,0 & 2,0 & 1,0 & 1,0 & 2,0 & 0,0010 \\
\hline Сферой услуг и бытового обслуживания & 2,0 & 2,0 & 3,0 & 2,0 & 2,0 & 3,0 & $* * *$ \\
\hline Сферой медицинского обслуживания & 3,0 & 2,0 & 4,0 & 2,0 & 2,0 & 3,0 & 0,0087 \\
\hline Проведением досуга & 2,0 & 2,0 & 3,0 & 2,0 & 1,0 & 2,0 & 0,0059 \\
\hline Возможностью проводить отпуск (каникулы) & 2,0 & 2,0 & 4,0 & 2,0 & 1,0 & 3,0 & 0,0182 \\
\hline Возможностью выбора места работы & 3,0 & 2,0 & 4,0 & 3,0 & 2,0 & 4,0 & $* * *$ \\
\hline Своим образом жизни в целом & 2,0 & 2,0 & 3,0 & 2,0 & 1,0 & 2,0 & 0,0001 \\
\hline
\end{tabular}

П р и м е ч а н и е. *** - Различия статистически незначимые.

Как показано в таблице 3, обследуемые основной группы фактически по всем социальным параметрам статистически значимо были более фрустрированы, чем студенты контрольной группы. Интерквартильный размах у них находился в диапазоне от «скорее удовлетворен» до «затрудняюсь ответить» и «скорее не удовлетворен». Одинаковая степень неудовлетворенности выявлена по параметрам неудовлетворенности: жилищно-бытовыми условиями, сферой услуг и возможностью выбора места работы. В 1-й подгруппе обследуемые были в большей степени не удовлетворены отношениями с родителями по сравнению с опрошенными 2-й подгруппы ( $\mathrm{p}=0,04)$.

Результаты исследования у студентовмедиков самоуважения по шкале Розенберга показаны на рисунке 1. Установлено, что у студентов-медиков, перенесших в дошкольном возрасте физическое и психологическое насилие, уровень самоуважения $\left(\mathrm{Me}=29 ; \mathrm{Q}_{25}-\mathrm{Q}_{75}=27-32\right)$ был статистически значимо ниже $(\mathrm{p}=0,000000)$, чем у воспитывавшихся в благоприятных условиях $\left(\mathrm{Me}=32 ; \mathrm{Q}_{25}-\mathrm{Q}_{75}=29-36\right)$. Если в контрольной группе он был высоким в большинстве случаев $(100-63,7 \%)$, то в основной группе - только у $30(35,3 \%): \chi^{2}=16,767, \mathrm{p}=0,0006 ; \mathrm{OR}=3,2$, $95 \% \mathrm{CI}=1,8-5,8$. Таким образом, воспитание в условиях жестокого обращения более чем в 3 раза повышает вероятность формирования личности с низким самоуважением.

Изучение суицидального поведения показало (табл. 4), что в общей совокупности в основной группе все виды суицидального поведения наблюдались у 45 (52,9\%) студентов-медиков, причем суицидальные попытки имели место в 5 $(8,3 \%)$ случаях. Кроме того, в течение последнего года суицидальное поведение (внутренние формы) имело место у 17 (20\%) студентов основной группы. 


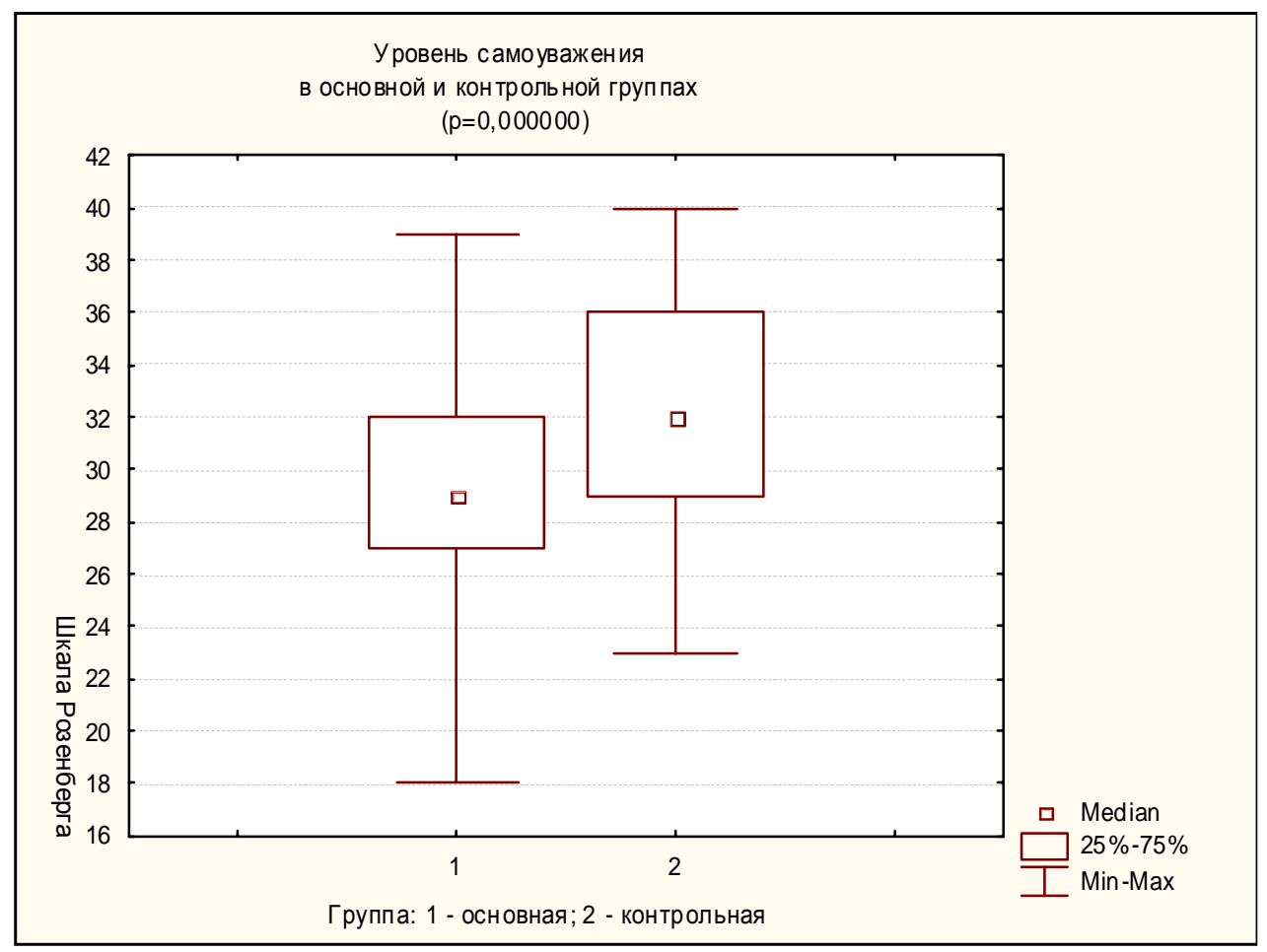

Р и с у н о к 1. Распределение студетов-медиков по уровню самоуважения в основной и контрольной группах

Т а б л и ц а 4

Распределение суицидального поведения по типам в основной и контрольной группах студентов-медиков

\begin{tabular}{|c|c|c|c|c|c|c|c|c|c|c|}
\hline \multirow{3}{*}{$\begin{array}{c}\text { Тип суицидального } \\
\text { поведения }\end{array}$} & \multicolumn{4}{|c|}{ Основная группа } & \multirow{2}{*}{\multicolumn{2}{|c|}{$\frac{\text { Контрольная группа }}{\text { 3-я подгруппа }}$}} & \multirow{2}{*}{\multicolumn{2}{|c|}{$\begin{array}{c}\text { Различия } \\
\text { [1-3] }\end{array}$}} & \multirow{2}{*}{\multicolumn{2}{|c|}{$\begin{array}{l}\text { Различия } \\
\text { [2-3] }\end{array}$}} \\
\hline & \multicolumn{2}{|c|}{ 1-я подгруппа } & \multicolumn{2}{|c|}{ 2-я подгруппа } & & & & & & \\
\hline & $\mathrm{n}$ & $\%$ & $\mathrm{n}$ & $\%$ & $\mathrm{n}$ & $\%$ & $\chi^{2}$ & $\mathrm{p}$ & $\chi^{2}$ & $\mathrm{p}$ \\
\hline Суицидальные замыслы & 11 & 44,0 & 25 & 41,7 & 30 & 19,1 & 6,297 & 0,012 & 7,799 & 0,006 \\
\hline Суицидальные намерения & 1 & 4,0 & 3 & 5,0 & 4 & 2,5 & - & - & - & - \\
\hline Суицидальные попытки & 3 & 12,0 & 2 & 3,3 & - & - & - & - & - & - \\
\hline $\begin{array}{l}\text { Суицидальные замыслы } \\
\text { в текущем году }\end{array}$ & 7 & 28,0 & 10 & 16,7 & 8 & 5,1 & - & - & - & - \\
\hline
\end{tabular}

Суицидальное поведение в 1-й подгруппе зарегистрировано в общей сложности (все формы) в 15 (60\%) случаях и приходилось на возрастной диапазон 13-24 $(17,6 \pm 3,0)$ года. Кроме того, в текущем году суицидальные замыслы выявлены у $28 \%$ студентов, в 1 (4\%) случае произошла суицидальная попытка.

Наиболее часто $(10-66,7 \%)$ причиной возникновения суицидального поведения являлись конфликты с родителями, часто сочетавшиеся с проблемами в учебе, конфликтными отношениями со сверстниками, конфликтами в интимно-личностной сфере (несчастная любовь, разрыв отношений). В трети (5 - 33,3\%) случаев суицидальное поведение мотивировалось утратой смысла жизни, подавленным настроением, проблемами со здоровьем. Характерно, что в данной подгруппе в $6(40,0 \%)$ случаях суицидальное поведение мотивировалось сочетанием суицидогенных конфликтов от 2 до 5.
Суицидальное поведение во 2-й подгруппе (без статистически значимых различий с 1-й подгруппой) наблюдалось у 30 (50\%) студентов и проявлялось в возрасте 8-24 $(14,9 \pm 3,6)$ года. В текущем году внутренние формы суицидального поведения имели место в $16,7 \%$ случаев. Суицидальное поведение мотивировалось в 11 $(36,7 \%)$ случаях конфликтами с родителями. В остальных случаях это были конфликтные отношения со сверстниками, проблемы с собственным здоровьем, утрата смысла жизни, беспричинное снижение настроения. Характерно, что в данной подгруппе только в $5(16,6 \%)$ случаях суицидальное поведение обусловливало сочетание конфликтов - от 2 до 3.

В контрольной группе суицидальное поведение наблюдалось в $34(21,7 \%)$ случаях, в текущем году - в $8(5,1 \%)$. Конфликты с родителями, явившиеся причиной суицидального поведения, зафиксированы в 4 (11,8\%) случаях. 
Сравнение частоты всех видов суицидального поведения в основной группе $(45-52,9 \%)$ с контрольной группой $(34-21,7 \%)$ показало статически значимые различия $\left(\chi^{2}=23,145\right.$, $\mathrm{p}=0,0005 ; \mathrm{OR}=4,1,95 \% \mathrm{CI}=2,2-7,5)$. Другими словами, перенесенное студентами-медиками в дошкольном возрасте физическое насилие более чем в 4 раза повышает вероятность суицидального поведения, чем у воспитывающихся в благоприятных условиях.

Более того, частота суицидального поведения в 1-ŭ noдгрупnе (60\%) статистически значимо выше $\left(\chi^{2}=14,227, \mathrm{p}=0,0008 ; \mathrm{OR}=5,4,95 \%\right.$ $\mathrm{CI}=2,1-14,4)$, чем в контрольной группе $(21,7 \%)$. Говоря иными словами, выраженное физическое насилие, перенесенное обследуемыми в дошкольном возрасте, более чем в 5 раз повышает вероятность суицидального поведения по сравнению с воспитывавшимися в благоприятных условиях.

Характерно, что конфликты с родителями как мотив суицидального поведения в 1-й подгруппе $(66,7 \%)$ встречались статистически значимо чаще $\left(\chi^{2}=4,882, \mathrm{p}=0,028 ; \mathrm{OR}=5,0,95 \%\right.$ $\mathrm{CI}=1,2-23,1)$, чем в контрольной группе (11,8\%). Приведенные данные свидетельствуют, что вероятность формирования суицидального поведения под влиянием конфликтов с родителями у лиц, перенесших выраженное физическое насилие в дошкольном возрасте, в 5 раз выше, чем у воспитывающихся в благоприятных условиях. Аналогичные результаты получены соответственно во 2-й подгруппе: $36,7 \%$ и $11,8 \%\left(\chi^{2}=4,207, p=0,040 ; \mathrm{OR}=4,3,95 \%\right.$ $\mathrm{CI}=1,1-19,2)$.

В 1-й подгруппе корреляционный анализ выявил слабую прямую корреляционную зависимость суицидального поведения со степенью неудовлетворенности отношениями с родителями ( $\mathrm{r}=0,401 \mathrm{p}=0,047)$, а во 2-й подгруппе обнаружена обратная корреляционная зависимость степени выраженности суицидального поведения с уровнем самоуважения по шкале Розенберга ( $\mathrm{r}=-0,403, \mathrm{p}=0,001)$.

\section{ЗАКЛЮЧЕНИЕ}

Таким образом, в результате исследования установлено, что перенесенное в дошкольном возрасте физическое насилие обусловливает вероятность формирования высокого уровня цинизма почти в 10 раз выше, чем при воспитании в благоприятных условиях. Перенесенное ребенком жестокое обращение в детстве способствовало формированию личности со средним уровнем враждебности по отношению к окружающим. Помимо того, перенесшие в детстве насилие по большинству социальных сфер были более фрустрированы и обнаруживали статистически значимо более низкий уровень самоуважения, чем их сверстники из благополучных семей. Установлено, что более чем в половине случаев $(52,9 \%)$ социальная дезадаптация и конфликтные отношения в семье обусловливали формирование суицидального поведения (внутренних форм $-47,1 \%$ и суицидальных попыток - 8,3\% случаев). Корреляционный анализ выявил слабую прямую зависимость суицидального поведения со степенью неудовлетворенности отношениями с родителями и обратную зависимость - с уровнем самоуважения. Полученные данные могут быть положены в основу дифференцированного подхода к профилактике суицидального поведения и социально-психологической дезадаптации лиц юношеского возраста, воспитывавшихся в условиях жестокого семейного воспитания.

\section{КОНФЛИКТ ИНТЕРЕСОВ}

Авторы заявляют об отсутствии возможных конфликтов интересов в связи с публикацией данной статьи.

\section{ИСТОЧНИК ФИНАНСИРОВАНИЯ}

Авторы подтверждают отсутствие финансирования и спонсорской поддержки при проведении данного исследования.

\section{СООТВЕТСТВИЕ ПРИНЦИПАМ ЭТИКИ}

Работа соответствует этическим стандартам Хельсинской декларации ВМА (протокол заседания этического комитета Медицинского института ФГАОУ ВО «Белгородский государственный национальный исследовательский университет» № 3 от 19 февраля 2015 г.).

\section{ЛИТЕРАТУРА}

1. Pinheiro S.P. World report on violence against children. Geneva: UN, Secretary-Generals study on violence against children, 2006, XIX: 364.

2. Hagemeister A.K., Nakajima Y., Beeman S.K., Edleson J.L., Baker P. Collaborating for woman and child safety: a training curriculum for multidisciplinary teams to enhance practice and policy when domestic violence and child maltreatment cooccur. St Paul: Minnesota Center Against Violence and Abuse, 2003.

3. Защита детей от насилия и жестокого обращения: межрегиональный тематический доклад. М.: Институт семьи и воспитания РАО, 2010: 36.

4. Колпакова Л.А. Насилие в семье (виктимологический аспект, вопросы дифференциации ответственности и законодательной техники). М.: Юрлитинформ, 2009: 196.

5. Плешкова Н.А. Семейное насилие и пути его преодоления в современном российском обще- 
стве: региональный аспект: автореф. дис. ... канд. социол. наук. Пенза, 2017: 22.

6. Касимова Л.Н., Демчева Н.К., Катерная Ю.Е. Влияние социальных факторов на психическое здоровье подростков. Вестник неврологии, психиатрии и нейрохирургии. 2017; 9: 3-13.

7. Бессчётнова О.В. Детско-родительские отношения в контексте семейного насилия: социологический аспект. Известия Волгоградского государственного педагогического университета. 2009; 3: 79-83.

8. Попова И.В. Опыт исследования проблемы семейного насилия. Научный диалог. 2012; 4: 124 135.

9. Белов В.Г., Парфенов Ю.А., Кирьянов В.М., Москаленко Г.В. Психологический статус подростков в раннем периоде после психической травмы, связанной с насилием в семье. Ученые записки университета им. П.Ф. Лесгафта. 2012; 2: 12-19.

10. Бадмаева В.Д., Чибисова И.А., Русинова С.С. Предикторы криминального поведения у несовершеннолетних подростков с психическими расстройствами (гендерный аспект). Вестник совета молодых учёных и специалистов Челябинской области. 2017; 3(1): 10-15.

11. Капитонова Н.С., Банщикова А.В., Кузык Я.С., Забозлаева И.В., Патракова А.А., Смирнова Т.А. Факторы риска суицидального поведения у девочек-подростков. Вестник совета молодых учёных и специиалистов Челябинской области. 2017; 3 (1): 24-30.

12. Rosiek A., Rosiek-Kryszewska A., Leksowski Ł., Leksowski K. Chronic stress and suicidal thinking among medical students. Int. J. Environ. Res. Public. Health. 2016; 13(2): 212. doi: 10.3390/ijerph13020212

13. Yusoff M.S., Abdul Rahim A.F., Baba A.A., Ismail S.B., Mat Pa M.N., Esa A.R. Prevalence and associated factors of stress, anxiety and depression among prospective medical students. Asian J. Psychiatr. 2013; 6(2): 128-133. doi: 10.1016/j.ajp.2012.09.012

14. Melaku L., Mossie A., Negash A. Stress among medical students and its association with substance use and academic performance. J. Biomed. Educ. 2015; 2015: Article ID: 149509, 1-9 149509. URL: https://www.hindawi.com/journals/jbe/2015/149509/. doi: 10.1155/2015/149509

15. Qamar K., Khan N.S., Bashir Kiani M.R. Factors associated with stress among medical students. $J$. Pak. Med. Assoc. 2015; 65(7): 753-755. https://www.ncbi.nlm.nih.gov/pubmed/26160086

16. Fares J., Saadeddin Z., Al Tabosh H., Aridi H., El Mouhayyar C., Koleilat M.K., Chaaya M., El As- mar K. Extracurricular activities associated with stress and burnout in preclinical medical students. J. Epidemiol. Glob. Health. 2016; 6(3): 177-185. doi: 10.1016/j.jegh.2015.10.003.

17. Popa-Velea O., Diaconescu L., Mihăilescu A., Jidveian Popescu M., Macarie G. Burnout and its relationships with alexithymia, stress, and social support among Romanian medical students: a cross-sectional study. Int. J. Environ. Res. Public. Health. 2017; 14(6): 560. URL: https://www.mdpi.com/16604601/14/6/560. doi: 10.3390/ijerph14060560

18. Al Kadri H.M., Al-Moamary M.S., Elzubair M., Magzoub M.E., AlMutairi A., Roberts C., van der Vleuten C. Exploring factors affecting undergraduate medical students' study strategies in the clinical years: a qualitative study. Adv. Health Sci. Educ. Theory Pract. 2011; 16 (5): 553-567. doi: 10.1007/s10459-010-9271-2

19. Reisbig A.M., Danielson J.A., Wu T.F., Hafen M.Jr., Krienert A., Girard D., Garlock J. A study of depression and anxiety, general health, and academic performance in three cohorts of veterinary medical students across the first three semesters of veterinary school. J. Vet. Med. Educ. 2012; 39(4): 341-58. doi: 10.3138/jvme.0712-065R.

20. Crego A., Carrillo-Diaz M., Armfield J.M., Romero M. Stress and academic performance in dental students: the role of coping strategies and examinationrelated self-efficacy. J. Dent. Educ. 2016; 80(2): 165172. https://www.ncbi.nlm.nih.gov/pubmed/26834134

21. Глазачев О.С. Психосоматическое здоровье студентов-медиков: возможности коррекции на основе оптимизации образовательных технологий. Вестник МГУ им. М.А. Шолохова. Социальноэкологические технологии. 2011; 1: 63-78.

22. Хритинин Д.Ф., Сумарокова М.А., Есин А.В., Самохин Д.В., Щукина Е.П. Условия формирования суицидального поведения у студентов медицинского вуза. Суицидология. 2016; 7 (2): 49-54.

23. Руженков В.А., Руженкова В.В. Некоторые аспекты суицидального поведения учащейся молодежи и возможные пути предупреждения. $\mathrm{Cu}$ бирский вестник психиатрии и наркологии. 2011; 4(67): 52-54.

24. Ruzhenkova V.V., Ruzhenkov V.A., Pahomov S.P., Zhernakov E.V., Lukyantseva I.S. Internal forms of suicidal behavior among medical students. Journal of Pharmacy Research. 2017; 11(12): 1579-1583.

Поступила в редакцию 28.02.2019 Утверждена к печати 8.04.2019 
Руженкова Виктория Викторовна - к.м.н., доцент кафедры психиатрии, наркологии и клинической психологии ФГАОУ ВО «Белгородский государственный национальный исследовательский университет» (SPIN 8424-7632, Researcher ID: E-9468-2018; Scopus Author ID: 56362612200; ORCID 0000-0002-1740-4904).

Руженков Виктор Александрович - д.м.н., профессор, заведующий кафедрой психиатрии, наркологии и клинической психологии ФГАОУ ВО «Белгородский государственный национальный исследовательский университет» (SPIN 12747247, Researcher ID: E-9496-2018, Scopus Author ID: 6507266676, ORCID 0000-00026903-9697).

Руженкова Виктория Викторовна, ruzhenkova@bsu.edu.ru

УДК 364.632-053.4:616.89-008.441.44:364-785.14:614.253.4

For citation: Ruzhenkova V.V., Ruzhenkov V.A. The outcomes of childhood physical abuse: influence on social adaptation and suicidal behavior of medical students. Siberian Herald of Psychiatry and Addiction Psychiatry. 2019; 2 (103): 55-64. https://doi.org/10.26617/1810-3111-2019-2(103)-55-64

\section{The outcomes of childhood physical abuse: influence on social adaptation and suicidal behavior of medical students}

\section{Ruzhenkova V.V., Ruzhenkov V.A.}

Belgorod National Research University

Pobedy Street 85, 308015, Belgorod, Russian Federation

\section{ABSTRACT}

Introduction. Violence in childhood is a negative social factor leading to social maladjustment, the formation of mental disorders and suicidal behavior. The aim of the study was to develop recommendations for the prevention of suicidal behavior among medical students on the basis of studying its relationship with the physical violence in the family during the preschool years. Material and methods. A continuous sample of 275 fifth-year students of the Medical Institute was examined using the medico-sociological and psychometric methods. There were $195(70.9 \%)$ females and $80(29.1 \%)$ males aged 20-32 (22.1 1 1.6) years. All students had a formally prosperous (well-to-do families, higher education from most parents, all working) families. A sample was divided into two groups: the main group included 85 (30.9\%) students who experienced physical abuse in preschool years (61 females and 24 males) and the control group - $157(57.1 \%)$ students without abuse in the preschool age (111 females and 46 males). The remaining 33 (12\%) students who indicated psychological abuse at preschool age were excluded. Results. Unfavorable conditions of upbringing resulted in a high level of cynicism and hostility, difficulties in social adaptation in most social spheres. In more than half of the cases (52.9\%), social maladjustment and conflicting relationships in the family led to the formation of suicidal behavior (internal forms $-47.1 \%$ and suicidal attempts $-8.3 \%$ of cases). Correlation analysis revealed a direct relationship of suicidal behavior with dissatisfaction of relationship with parents and the opposite relationship with the level of self-esteem. Conclusion. The data could be used as a basis for a differentiated approach to the prevention of suicidal behavior and socio-psychological maladjustment of young persons who were brought up in conditions of family cruelty.

\section{Keywords: medical students, physical abuse, preschool age, social frustration, self-esteem, suicidal behavior.}

\section{REFERENCES}

1. Pinheiro S.P. World report on violence against children. Geneva: UN, Secretary-Generals study on violence against children, 2006, XIX: 364.

2. Hagemeister A.K., Nakajima Y., Beeman S.K., Edleson J.L., Baker P. Collaborating for woman and child safety: a training curriculum for multidisciplinary teams to enhance practice and policy when domestic violence and child maltreatment cooccur. St Paul: Minnesota Center Against Violence and Abuse, 2003.

3. Zashchita detey ot nasiliya i zhestokogo obrashcheniya: mezhregional'nyy tematicheskiy doklad [Protecting children from violence and abuse: interregional thematic report]. Moscow: Institute of family and education Russian Education Academy, 2010: 36 (in Russian).

4. Kolpakova L.A. Nasiliye v sem'ye (viktimologicheskiy aspekt, voprosy differentsiatsii otvetstvennosti i zakonodatel'noy tekhniki) [Family violence (victimological aspect, issues of differentiation of responsibility and legislation)]. Moscow: Yurlitinform, 2009: 196 (in Russian).

5. Pleshkova N.A. Semejnoe nasilie i puti ego preodolenija $\mathrm{v}$ sovremennom rossijskom obshhestve: regional'nyj aspekt [Family violence and ways to overcome it in modern Russian society: the regional aspect]: thesis abstract of candidate of sociological Sciences. Penza, 2017: 22 (in Russian). 
6. Kasimova L.N., Demcheva N.K., Katernaya Yu.E. Vliyaniye sotsial'nykh faktorov na psikhicheskoye zdorov'ye podrostkov [Influence of social factors on mental health of adolescents]. Vestnik nevrologii, psikhiatrii i neyrokhirurgii - Bulletin of Neurology, Psychiatry and Neurosurgery. 2017; 9: 3-13 (in Russian).

7. Besschetnova O.V. Detsko-roditel'skiye otnosheniya $v$ kontekste semeynogo nasiliya: sotsiologicheskiy aspect [Parent-children relationship in the context of family violence: sociological aspect]. Izvestiya Volgogradskogo gosudarstvennogo pedagogicheskogo universiteta - News of the Volgograd State Pedagogical University. 2009; 3: 79-83 (in Russian).

8. Popova I.V. Opyt issledovaniya problemy semeynogo nasiliya [Experience in studying the problem of family violence]. Nauchnyy dialog - Scientific Dialogue. 2012; 4: 124-135 (in Russian).

9. Belov V.G., Parfenov Yu.A., Kir'yanov V.M., Moskalenko G.V. Psikhologicheskiy status podrostkov v rannem periode posle psikhicheskoy travmy, svyazannoy s nasiliyem v sem'ye [The psychological status of adolescents in the early period after mental trauma associated with domestic violence]. Uchenyye zapiski universiteta im. P.F. Lesgafta Scientific Notes of the University named after P.F. Lesgaft. 2012; 2: 12-19 (in Russian).

10. Badmayeva V.D., Chibisova I.A., Rusinova S.S. Prediktory kriminal'nogo povedeniya u nesovershennoletnikh podrostkov s psihicheskimi rasstroystvami (gendernyy aspekt) [Predictors of criminal behavior in juvenile adolescents with mental disorders (gender aspect)]. Vestnik soveta molodykh uchënykh $i$ spetsialistov Chelyabinskoy oblasti - Bulletin of the Council of Young Scientists and Specialists of the Chelyabinsk Region. 2017; 3(1): 10-15 (in Russian).

11. Kapitonova N.S., Banshchikova A.V., Kuzyk Ya.S., Zabozlayeva I.V., Patrakova A.A., Smirnova T.A. Faktory riska suitsidal'nogo povedeniya u devochek-podrostkov [Risk factors of suicide behaviour in girls-teenagers]. Vestnik soveta molodykh uchënykh $i$ spetsialistov Chelyabinskoy oblasti - Bulletin of the Council of Young Scientists and Specialists of the Chelyabinsk Region. 2017; 3 (1): 24-30 (in Russian).

12. Rosiek A., Rosiek-Kryszewska A., Leksowski Ł., Leksowski K. Chronic stress and suicidal thinking among medical students. Int. J. Environ. Res. Public. Health. 2016; 13(2): 212. doi: 10.3390/ijerph13020212

13. Yusoff M.S., Abdul Rahim A.F., Baba A.A., Ismail S.B., Mat Pa M.N., Esa A.R. Prevalence and associated factors of stress, anxiety and depression among prospective medical students. Asian J. Psychiatr. 2013; 6(2): 128-133. doi: 10.1016/j.ajp.2012.09.012

14. Melaku L., Mossie A., Negash A. Stress among medical students and its association with substance use and academic performance. J. Biomed. Educ.
2015; 2015: Article ID: 149509, 1-9 149509. URL: https://www.hindawi.com/journals/jbe/2015/149509/. doi: 10.1155/2015/149509

15. Qamar K., Khan N.S., Bashir Kiani M.R. Factors associated with stress among medical students. $J$. Pak. Med. Assoc. 2015; 65(7): 753-755. https://www.ncbi.nlm.nih.gov/pubmed/26160086

16. Fares J., Saadeddin Z., Al Tabosh H., Aridi H., El Mouhayyar C., Koleilat M.K., Chaaya M., El Asmar K. Extracurricular activities associated with stress and burnout in preclinical medical students. J. Epidemiol. Glob. Health. 2016; 6(3): 177-185. doi: 10.1016/j.jegh.2015.10.003.

17. Popa-Velea O., Diaconescu L., Mihăilescu A., Jidveian Popescu M., Macarie G. Burnout and its relationships with alexithymia, stress, and social support among Romanian medical students: a cross-sectional study. Int. J. Environ. Res. Public. Health. 2017; 14(6): 560. URL: https://www.mdpi.com/16604601/14/6/560. doi: 10.3390/ijerph14060560

18. Al Kadri H.M., Al-Moamary M.S., Elzubair M., Magzoub M.E., AlMutairi A., Roberts C., van der Vleuten C. Exploring factors affecting undergraduate medical students' study strategies in the clinical years: a qualitative study. Adv. Health Sci. Educ. Theory Pract. 2011; 16 (5): 553-567. doi: 10.1007/s10459-010-9271-2

19. Reisbig A.M., Danielson J.A., Wu T.F., Hafen M.Jr., Krienert A., Girard D., Garlock J. A study of depression and anxiety, general health, and academic performance in three cohorts of veterinary medical students across the first three semesters of veterinary school. J. Vet. Med. Educ. 2012; 39(4): 341-58. doi: 10.3138/jvme.0712-065R.

20. Crego A., Carrillo-Diaz M., Armfield J.M., Romero M. Stress and academic performance in dental students: the role of coping strategies and examinationrelated self-efficacy. J. Dent. Educ. 2016; 80(2): 165172. https://www.ncbi.nlm.nih.gov/pubmed/26834134

21. Glazachev O.S. Psikhosomaticheskoye zdorov'ye studentov-medikov: vozmozhnosti korrektsii na osnove optimizatsii obrazovatel'nykh tekhnologiy [Psychosomatic health of medical students: correction on the base of educational technologies optimization]. Vestnik MGU im. M.A. Sholohova. Sotsial'no-ekologicheskiye tekhnologii - Bulletin of Moscow State University named after M.A. Sholokhov. Socio-environmental Technologies. 2011; 1: 63-78 (in Russian).

22. Khritinin D.F., Sumarokova M.A., Esin A.V., Samokhin D.V., Shchukina E.P. Usloviya formirovaniya suitsidal'nogo povedeniya u studentov meditsinskogo vuza [Conditions for the formation of suicidal behavior among medical students]. Suitsidologiya - Suicidology. 2016; 7 (2): 49-54 (in Russian).

23. Ruzhenkov V.A., Ruzhenkova V.V. Nekotoryye aspekty suitsidal'nogo povedeniya uchashcheysya molodezhi i vozmozhnyye puti preduprezhdeniya [Some aspects of suicidal behavior of students and possible ways to prevent]. Sibirskiy vestnik 
psikhiatrii $i$ narkologii - Siberian Herald of Psychiatry and Addiction Psychiatry. 2011; 4(67): 5254 (in Russian).

24. Ruzhenkova V.V., Ruzhenkov V.A., Pahomov S.P., Zhernakov E.V., Lukyantseva I.S. Internal forms of suicidal behavior among medical students. Journal of Pharmacy Research. 2017; 11(12): 1579-1583.

Received February 28.2019

Accepted April 08.2019

Ruzhenkova Viktoriya V. - PhD, Associate Professor, Department of Psychiatry, Narcology and Clinical Psychology, "Belgorod State National Research University", Belgorod, Russian Federation (SPIN 8424-7632, Researcher ID: E9468-2018; Scopus Author ID: 56362612200; ORCID 0000-0002-1740-4904).

Ruzhenkov Viktor A. - MD, Prof., Head of the Department of Psychiatry, Narcology and Clinical Psychology, "Belgorod State National Research University", Belgorod, Russian Federation (SPIN 12747247, Researcher ID: E9496-2018, Scopus Author ID: 6507266676, ORCID 0000-0002-6903-9697).

$\triangle$ Ruzhenkova Viktoriya V., ruzhenkova@bsu.edu.ru 